\title{
PROCESSING EFFECTS ON THE FAILURE OF EBPVD TBCS ON MCIAIY AND PLATINUM ALUMINIDE BOND COATS
}

\author{
N. M. Yanar, M.J. Stiger, G. H. Meier and F. S. Pettit \\ Materials Science and Engineering Department, University of Pittsburgh, \\ Pittsburgh, PA, 15261
}

\begin{abstract}
Thermal barrier coatings (TBCs) compused of ytira stabilized zirconia (YSZ) deposited via electron beam physical vapor deposition (EBPVD) on MCrAlY and platinum diffusion aluminide bond coats on the superalloy Rene N5 have been compared in cyclic oxidation in air at $1100^{\circ} \mathrm{C}$. The MCrAlY bond coats were fabricated by using several different plasma spray processes. The TBCs on the MCrAlY bond coats had shorter lives compared to the TBCs on the platinum aluminide bond coats. This difference in TBC performance is proposed to be caused by the presence of other oxides than alumina on the MCrAIY bond coats which caused the toughness of the TBCTGO-bond coat region to be reduced. Processing variables which affect TBC performances are discussed.
\end{abstract}

Superalloys 2000

Edited by T.M. Pollock, R.D. Kissinger, R.R. Bowman

K.A. Green, M. McLean, S. Olson, and J.J. Schirra

TMS (The Minerals, Metals \& Materials Society), 2000 


\section{Introduction}

It has been documented in numerous publications that thermal barrier coatings (TBCs) consisting of a $6-8 \mathrm{wt} . \% \mathrm{Y}_{2} \mathrm{O}_{3}$ stabilized $\mathrm{ZrO}_{2}$ (YSZ) are an effective method to increase the useful lifetimes of high temperature components such as combustion liners and vanes and blades in gas turbines $(1,2)$. Such coatings are usually applied in conjunction with a bond coat, as shown in Figure 1, to superalloy hardware. While it is clear that TBCs are effective coatings, the fabrication procedures that will result in optimum lives require better definition. The mechanics by which TBCs fail are not clear. The paper by Marcin and Bose provides a chronological description of the progression of TBC technology (1). Generation I TBCs consisted of air plasma spray (APS) MCrAlY bond coats and air plasma spray YSZ TBCs. Failure was caused by thermally induced stresses and occurred in the air plasma sprayed bond coats. Improved performances were obtained in Generation II TBCs by using low pressure plasma spray (LPPS) MCrAIY bond coats and air plasma spray YSZ TBCs. The failure of the Generation II TBCs occurred predominantly in the YSZ TBC. Generation III TBCs consisted of a LPPS MCrAIY bond coat, or a platinum modified aluminide bond coat, and a YSZ TBC deposited by using electron beam physical vapor deposition. In Generation III TBCs failure was no longer in the TBC but rather along the interface between bond coat and the thermally grown oxide (TGO) that forms during exposure at elevated temperatures. The progression of technology from Generation I to Generation III TBCs certainly represent the development of improved TBC systems, however numerous questions remain unanswered concerning the mechanisms of TBC failures. Generation II and III TBCs consist of YSZ TBCs deposited via different processes, Figure 2, and the TBCs are usually of different thicknesses. For example, the TBCs deposited via APS are usually on the order of $300 \mu \mathrm{m}$ whereas the TBCs prepared by EBPVD are between 100 and $150 \mu \mathrm{m}$ in thickness. The effect of this TBC thickness must be considered in comparing Generation II and Generation III TBC failures. Generation III TBCs may use either MCrAIY bond coats, deposited via LPPS or some other type of spray process that does not cause oxidation of the MCrAIY powder, or platinum modified diffusion aluminide bond coats. There are data in the literature to indicate that TBCs with platinum aluminide bond coats are better than those on MCrAlY bond coats (3). Nevertheless, there are TBCs being used in service that have MCrAIY bond coats. Moreover, results are also available that show in some cases TBC performance using MCrAIY bond coats can be exceptional (4). In order to understand the effects of different process variables on TBC performance it is necessary to investigate and describe in detail TBC failure mechanisms. This paper is concerned with the failure of EBPVD YSZ TBCs on MCrAIY and platinum aluminide bond coats after cyclic oxidation at $1100^{\circ} \mathrm{C}$ in air.

\section{Characterization of As Processed TBCs}

The TBC specimens, Figure 1, were prepared by depositing YSZ via EBPVD on either MCrAIY or platinum aluminide bond coats. The superalloy substrate was Rene N5 (Ni-7.5 Co-7.0 Cr-1.5 Mo5.0 W-3.0 Re 6.5 Ta-6.2 Al- $15 \mathrm{Hf}-0.05 \mathrm{C}-0.004 \mathrm{~B}-0.01 \mathrm{Y}$ in wt.\%). All of the TBCs were prepared in the same coater. The YSZ had a segmented structure with a cellular structure within segments, Figure 3 . The cellular structure became more developed upon exposure to elevated temperatures. At times defects were evident in the TBC, Figure 4 , but such defects were not numerous and have not been found to contribute to failures.

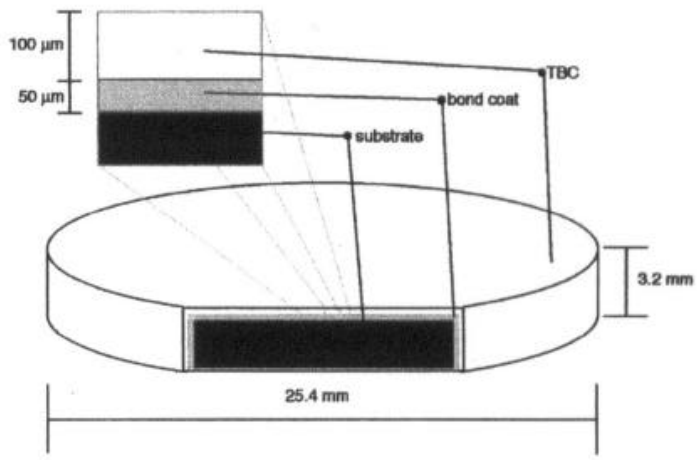

Figure 1. Schematic to show the relationship between TBC, bond coat and superalloy on specimens used in this program
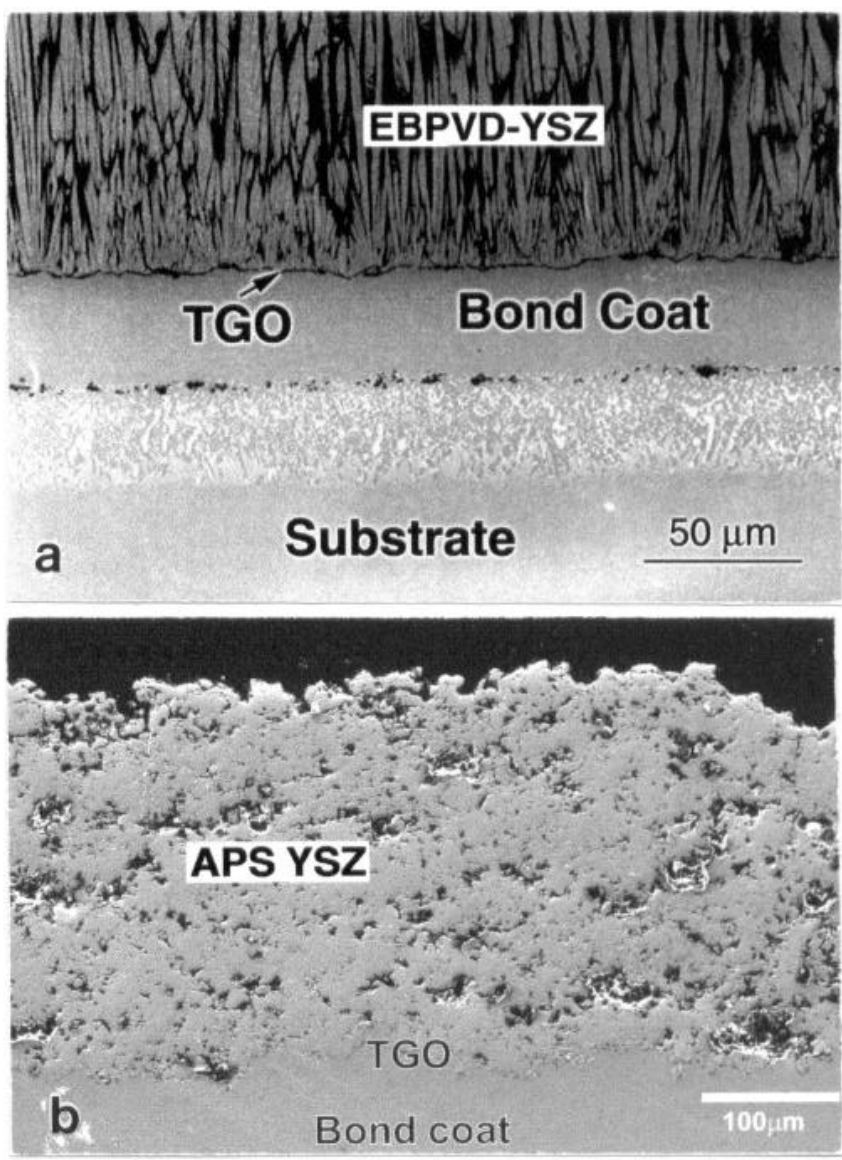

Figure 2. Photomicrographs showing typical electron beam physical vapor deposited (EBPVD) and air plasma sprayed (APS) yttria stabilized zirconia thermal barrier coatings. The EBPVD TBC consists of segmented,columnar grains whereas the APS TBC is composed of a particle like structure due to fusing of the YSZ powders. 
Three types of MCrAlY bond coats were used. The compositions of these coatings, as well as the technique via which they were deposited, are presented in Table I. Three platinum aluminide bond coats were studied. All three bond coats were fabricated via the same general approach, namely a platinum coating was electrolytically deposited on the N5 substrate followed by aluminizing using a high temperature low aluminum activity process. Bond coat $\mathrm{A}$ was deposited by one manufacturer and bond coats $\mathrm{B}$ and $\mathrm{C}$ by another. The difference between bond coats $\mathrm{B}$ and $\mathrm{C}$ was that two different electrolytic techniques were used to deposit the platinum coatings. The surface of all bond coats were prepared by grit blasting using alumina powder prior to TBC deposition.

Photographs showing the as processed TBCs with MCrAlY bond coats are presented in Figures 5,6 and 7. A thin TGO was evident as well as $\beta(\mathrm{Ni}, \mathrm{Co}, \mathrm{Al})$ and $\gamma$ (nickel solid solution) phases in the coatings beneath the TGOs. In all of these coatings nickel and chromium in addition to aluminum was detected in the TGOs on these TBCs. However, the TGOs were very thin and the nickel and chromium may have come from the bond coat. The TBCs on the platinum aluminide bond coats all had similar structures, Figure 8a. However, the aluminide coating thickness on A was less than on $\mathrm{B}$ and $\mathrm{C}$, and the platinum content at the bond coatTGO interface was greater in C than in B. All of these TBCs contained a thin TGO, Figure $8 \mathrm{~b}$, for which the thickness varied by a substantial amount. Such variations in the TGO thicknesses were also observed on the MCrAlY bond coats and may have been caused by grit blasting. The TGOs on the platinum aluminide bond coats were usually thicker than those on the MCrAlY bond coats and contained only aluminum and oxygen.

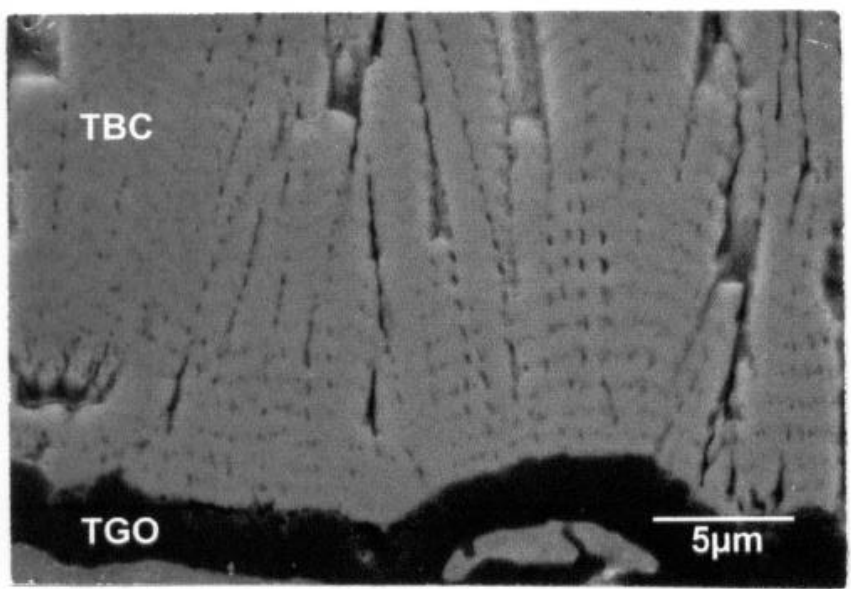

Figure 3. Scanning micrograph of a TBC showing cellular structure that developed in the TBC upon exposure for $60 \mathrm{hrs}$ at $1200^{\circ} \mathrm{C}$

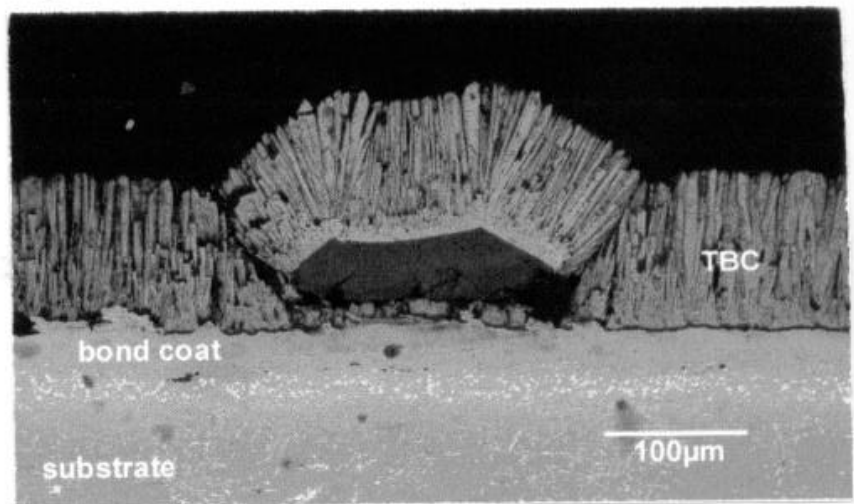

Figure 4. As processed YSZ TBC on a platinum aluminide bond coat showing a defect that was present in the TBC.
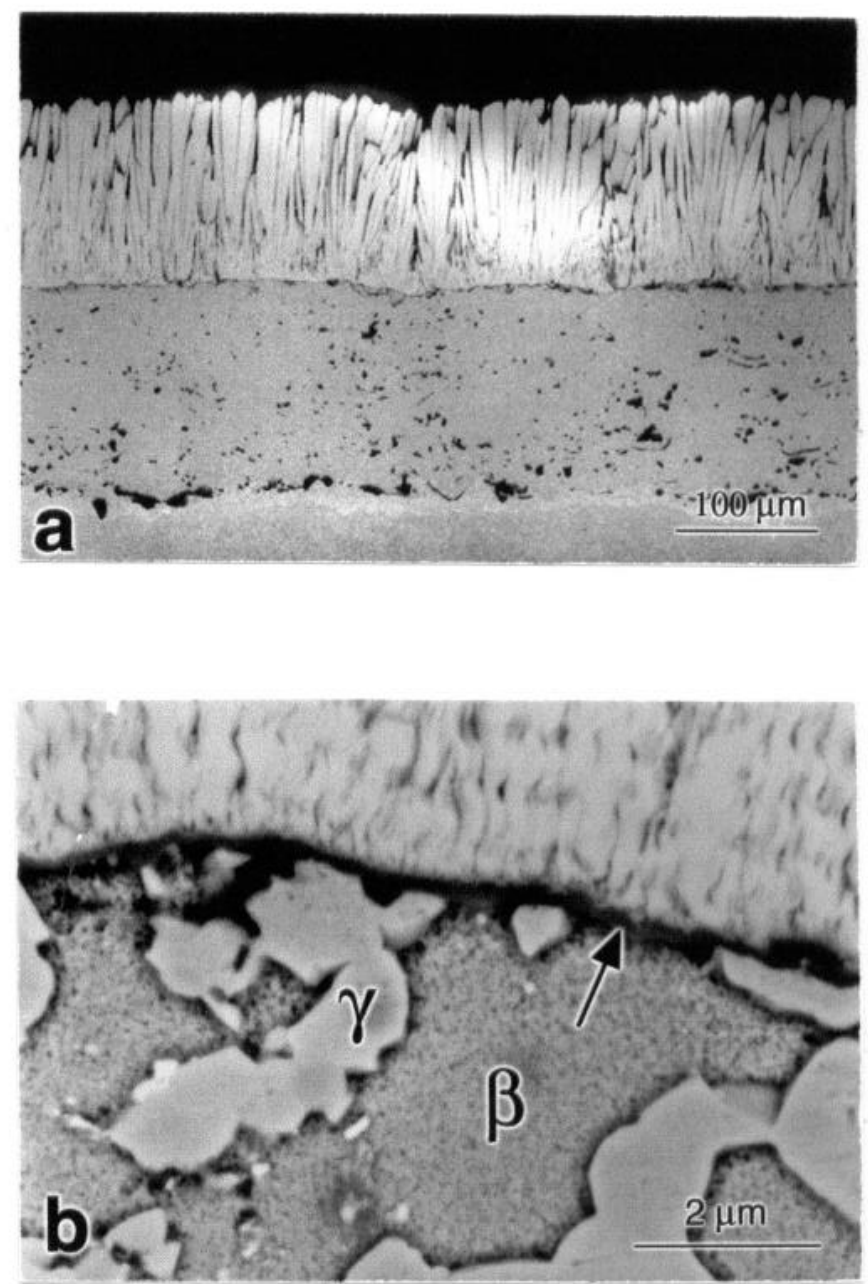

Figure 5. The as processed LN-11 bond coat with a TBC was uniform in thickness and contained some porosity and oxide inclusions, (a). A thin TGO was evident between the TBC and the bond coat, arrow (b). The bond coat contained $\beta$ and $\gamma$ phases. 

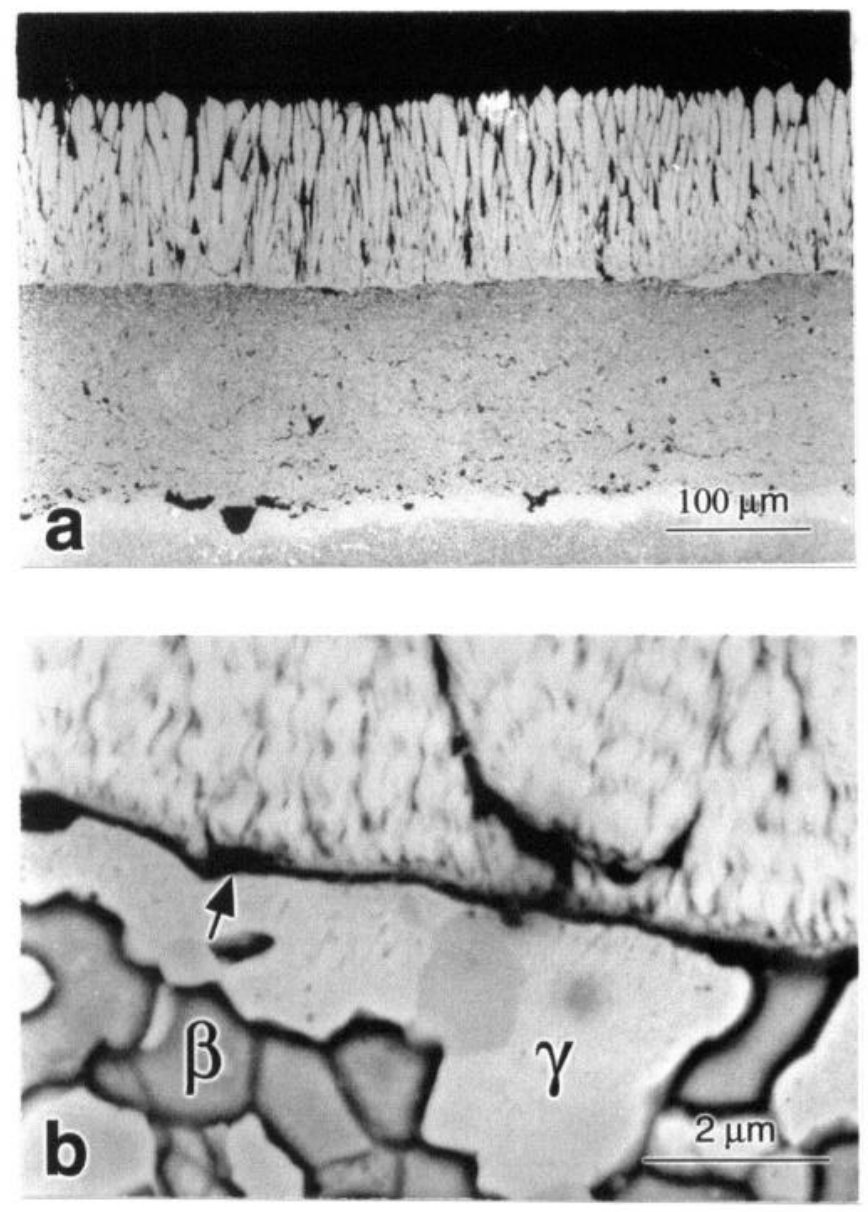

Figure 6. The TBC on the LN72 coating was uniform and some porosity and oxide inclusions were evident in the bond coat, (a). A TGO was evident between the TBC and bond coat in which some variations in thickness were evident, arrow, (b).

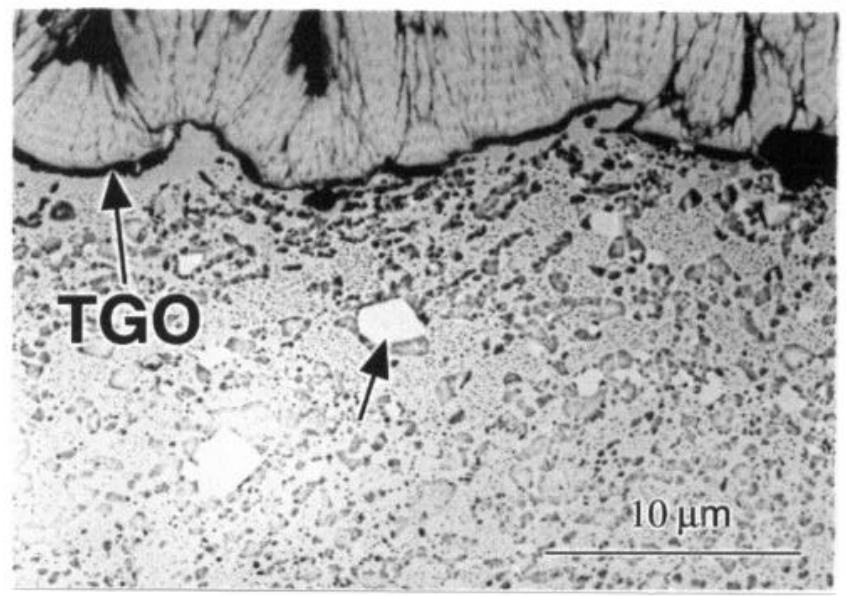

Figure 7. The TBC on the as processed $\mathrm{BC} 52$ bond coat contained an irregular TGO. Cr-Re particles were evident in this bond coat (arrow) along with both $\beta$ and $\gamma$ phases
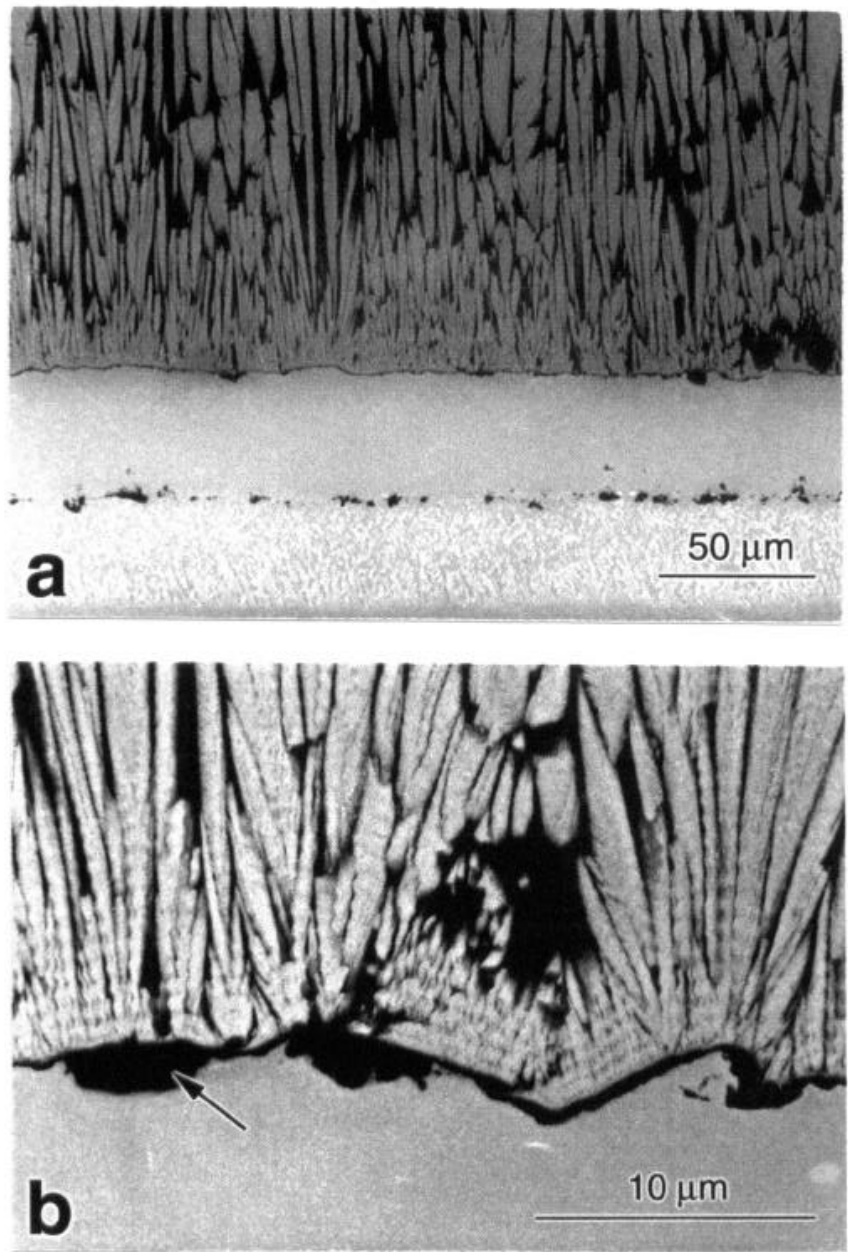

Figure 8. A typical as processed TBC system is shown in, (a). The TGOs on the platinum aluminide bond coats exhibited a variable thickness, arrow, (b), and were thicker than the TGOs on the as processed MCrAIY bond coats.

\section{Experimental Oxidation Conditions}

All of the TBCs were exposed to cyclic oxidation conditions in a bottom loading furnace at $1100^{\circ} \mathrm{C}$ in air. This furnace had a platform upon which all of the specimens could be exposed simultaneously. The test cycle consisted of 10 minutes heating to temperature, 45 minutes at temperature followed by 10 minutes of forced air cooling. All of the specimens were examined at various time intervals by using optical metallography. The observations were directed at determining when and where cracking was evident in the TBCs. Upon termination of testing the fracture surfaces of failed specimens were characterized by using scanning electron microscopy. Sections through the TBCs and bond coats were prepared for examination via optical metallography and the SEM. 
Table I. Compositions of MCrAlY Coatings

\begin{tabular}{|l|l|l|l|l|l|l|l|l|l|l|l|l|}
\hline Coating & $\mathrm{Ni}$ & $\mathrm{Co}$ & $\mathrm{Al}$ & $\mathrm{Cr}$ & $\mathrm{Hf}$ & $\mathrm{Y}$ & $\mathrm{Si}$ & $\mathrm{O}$ & $\mathrm{C}$ & $\mathrm{Fe}$ & $\mathrm{Re}$ & $\mathrm{Ta}$ \\
\hline D-Gun (LN-72) & 44.4 & 22.95 & 13.82 & 16.59 & - & 0.57 & - & 0.9 & 0.58 & - & - & - \\
\hline $\begin{array}{l}\text { Shrouded Argon } \\
\text { (LN-11) }\end{array}$ & 48.0 & 21.78 & 12.58 & 16.45 & - & 0.43 & - & 0.16 & - & - & - & - \\
\hline $\begin{array}{l}\text { Shrouded Argon } \\
\text { (BC-52) }\end{array}$ & 55.4 & 9.95 & 6.55 & 17.31 & 0.58 & 0.28 & 1.19 & 0.012 & - & - & 2.03 & 6.11 \\
\hline
\end{tabular}

Table II. Exposure Cycles to Failure of TBCs

\begin{tabular}{|c|c|}
\hline Bond Coat & Exposure Cycles \\
\hline Shrouded Argon Plasma MCrAIY (LN-11) & 76,102 \\
\hline D-Gun MCrAlY (LN-72) & 102,139 \\
\hline Shrouded Argon Plasma MCrAlY (BC-52) & 291 \\
\hline Platinum Aluminide (A) & 1005 \\
\hline Platinum Aluminide (B) & 1212 \\
\hline Platinum Aluminide (C) & 1280 \\
\hline
\end{tabular}

\section{Failure Characteristics of the Cyclically Oxidized TBCs}

The cycles to failure of the TBCs with differcnt bond coats are presented in Table II. The TBCs on MCrAlY bond coats deposited via the $\mathrm{LN}-11$ and $\mathrm{LN}-72$ processes failed after essentially the same number of cycles. The BC 52 composition bond coat had a slightly longer life. The TBCs on platinum aluminide bond coats $B$ and $C$ had longer lives than the TBCs on bond coat $\mathrm{A}$.

The fracture surfaces exposed upon failure of the TBCs with MCrAlY bond coats are shown in Figures $9 a, b$ and $c$ for $L N-11$, LN-72 and BC-52, respectively. The fractures have proceeded along the TGO-bond coat interfaces with numerous excursions into the TGOs and TBCs. The excursions into the TGOs occurred where the TGO extended into the bond coat due to oxidation of elements such as yttrium, hafnium and tantalum, Figure 10a, b and $c$. The TGOs that formed on the MCrAlY bond coats were not pure alumina but consisted of other oxides such as spinels $\left(\mathrm{NiCr}_{2} \mathrm{O}_{4}, \mathrm{NiAl}_{2} \mathrm{O}_{4}\right)$, and oxides containing yttrium, hafnium and/or tantalum. Aluminum depletion of the MCrAlY bond coats was not the cause of TBC failure since the aluminum rich $\beta$ phase was present in these bond coats at the time of TBC failure, Figure 11 .

Specimens of the TBCs on the platinum aluminide bond coats were examined prior to failure after 758 cycles at $1100^{\circ} \mathrm{C}$, and after failure. In Figure 12 a cross section of the TBC on platinum aluminide $C$ is presented after 758 cycles. The TGO was pure alumina and some deformation of the aluminide bond coat was evident as indicated by undulations that developed at points where the TBC fractured, Figure $12 \mathrm{~b}$. The aluminide bond coat contained predominantly $\beta$ phase but $\gamma^{\prime}$ was evident in the bond coat adjacent to the TGO, Figure 12c. Similar features were evident in the TBCs on platinum aluminide bond coats $A$ and $B$, but the TBCs became detached during metallographic preparation. Failures occurred at the TGO-bond coat interfaces with numerous excursions into the TGOs and TBCs, Figures 13a and b. At times a zone was evident in the outer part of the TGO that contained a mixture of alumina and YSZ, Figure 13b. Such zones have been observed in TGOs previously (5).

A typical surface of a platinum aluminide bond coat after spalling of the TBC is shown in Figure 14. It is evident that fracture has occurred in the TBC and the TGO, as well as along the TGO-bond coat interface but since failure occurred during testing, the exposed bond coat has been oxidized.

\section{Mechanisms of TBC Failures}

The results clearly show that Generation III TBCs do not fail by cracking solely along the TGO-bond coat interface. In the case of the MCrAlY bond coats the TGOs in the as processed condition may have contained spinels, and other oxides than alumina developed during oxidation. The absence of relatively pure alumina TGOs is believed to be responsible for the short lives of TBCs on the MCrAlY bond coats. As processed TBCs un MCrAlY bond coats were delaminated by using an indent test (7), but this test did not cause delamination of the TBC on as processed platinum aluminide bond coats. These results show that the interfacial toughness in the TBC-TGO-bond coat region is greater for the TBCs on the platinum aluminide bond coats compared to the MCrAlY bond coats. More work is required to determine where fracture of the TBC initiates, but it appcars to involve in some way either the spinel phases and/or the oxides of tantalum and hafnium. Therefore fracture may initiate in the TGO. The lives of TBCs on MCrAlY bond coats should be increased if pure alumina TGOs are developed on these bond coats. Work is in progress to test this hypothesis. 


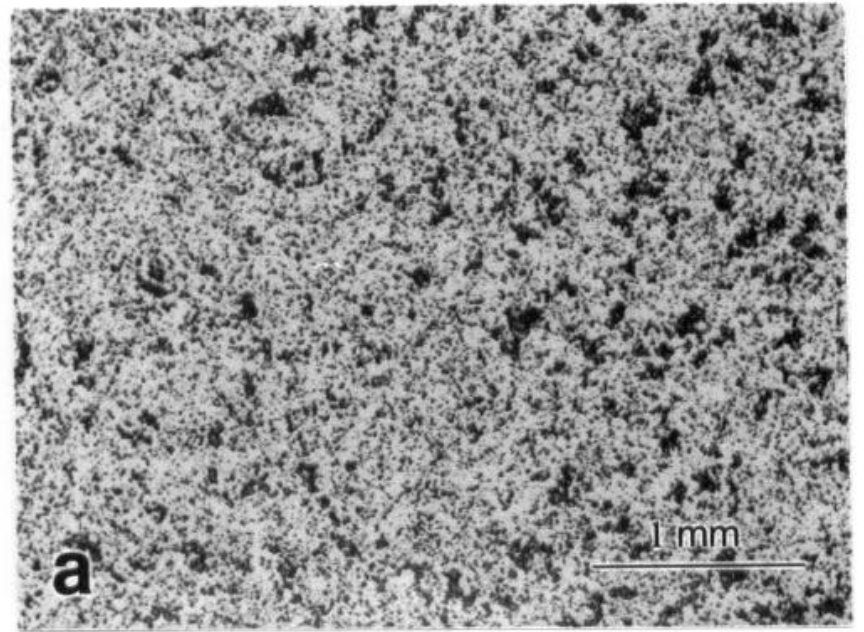

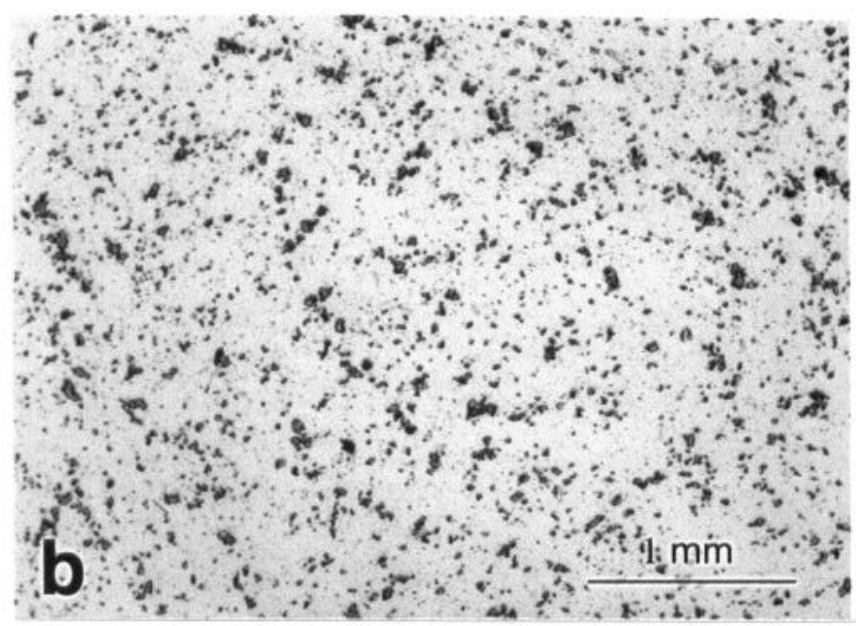

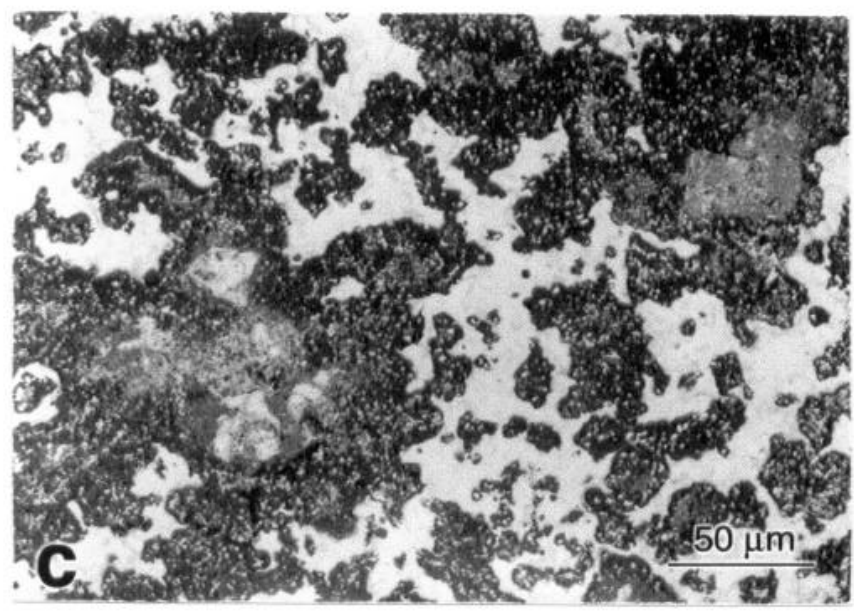

Figure 9. Surfaces exposed upon failure of the TBCs on LN-11, (a), LN-72, (b) and BC-52, (c). The failures have exposed bare bond coat (white areas) with numerous excursions into the TGOs and TBCs.
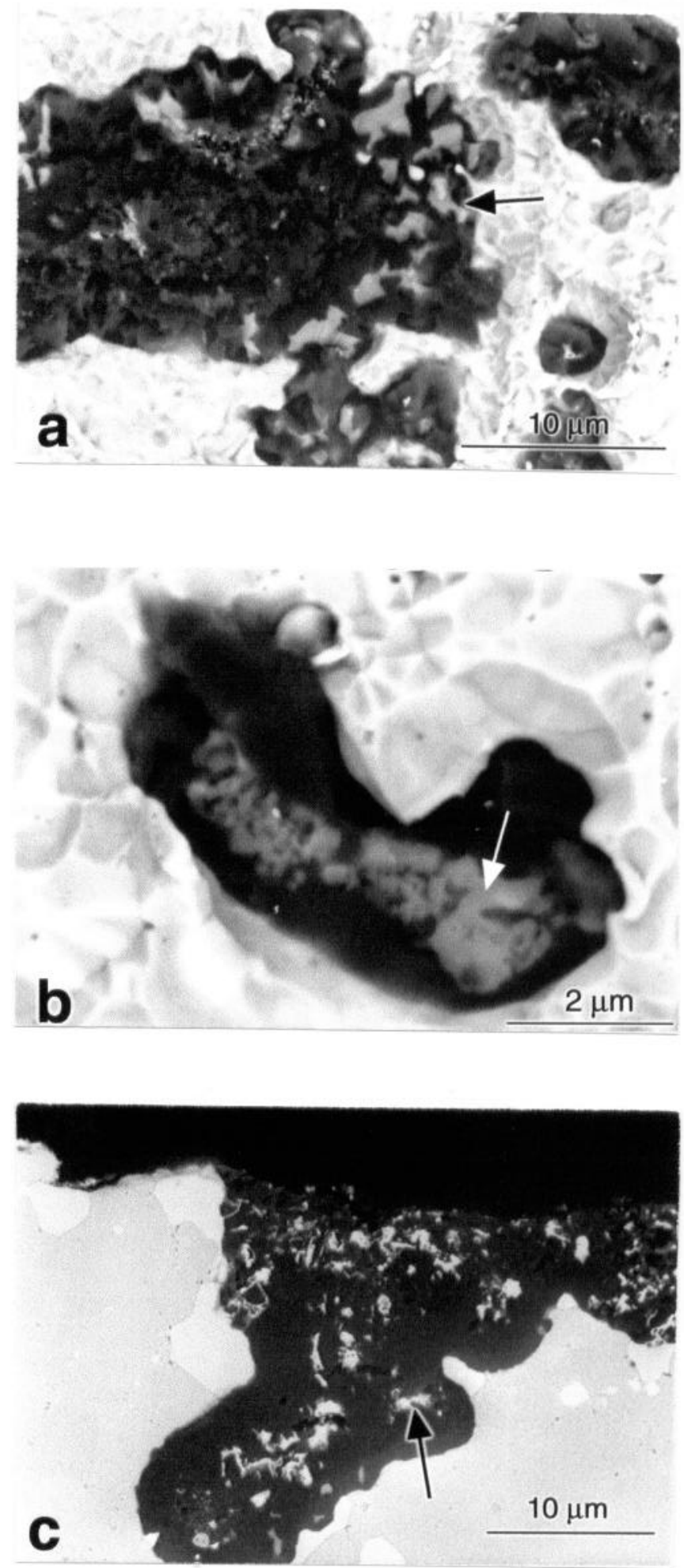

Figure 10. Some of the dark areas in Figure 9 are shown at higher magnifications for LN-11, (a), LN-72, (b), and BC-52, (c). The TGO on LN-11 contained alumina with oxides of yttrium and hafnium, arrow (a). The TGO on LN-72 bond coat contained ytrrium oxides, arrow (b), and the TGO in BC-52 was permeated with oxides of hafnium and tantalum, arrow (c). 


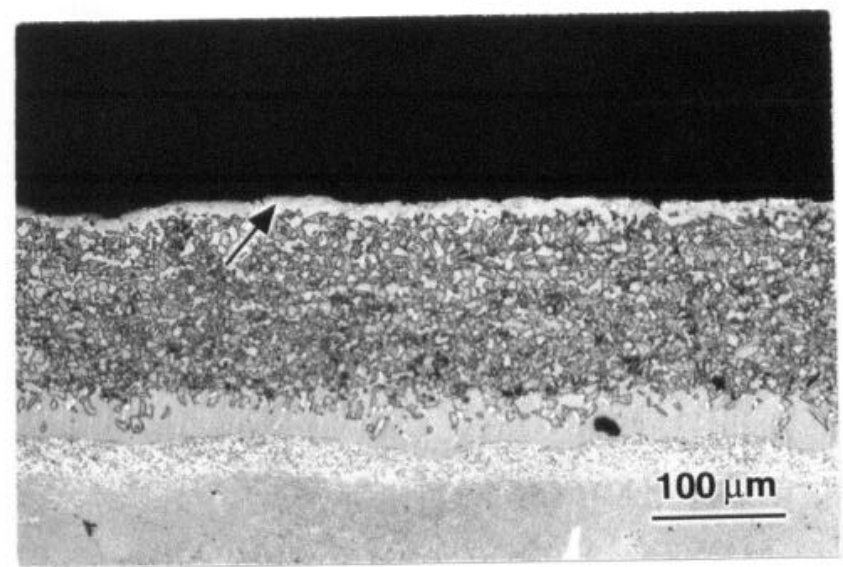

Figure 11. Photomicrograph showing the bond coat on LN-72 after failure of the TBC $\left(139 \mathrm{hrs}\right.$ at $\left.1100{ }^{\circ} \mathrm{C}\right)$. The $\beta$ phase has been depleted from a very thin layer (arrow) of the coating. A similar zone was evident after failure of the TBC on LN-11 whereas the $\beta$ phase was removed from $50 \%$ of the BC-52 bond coat.
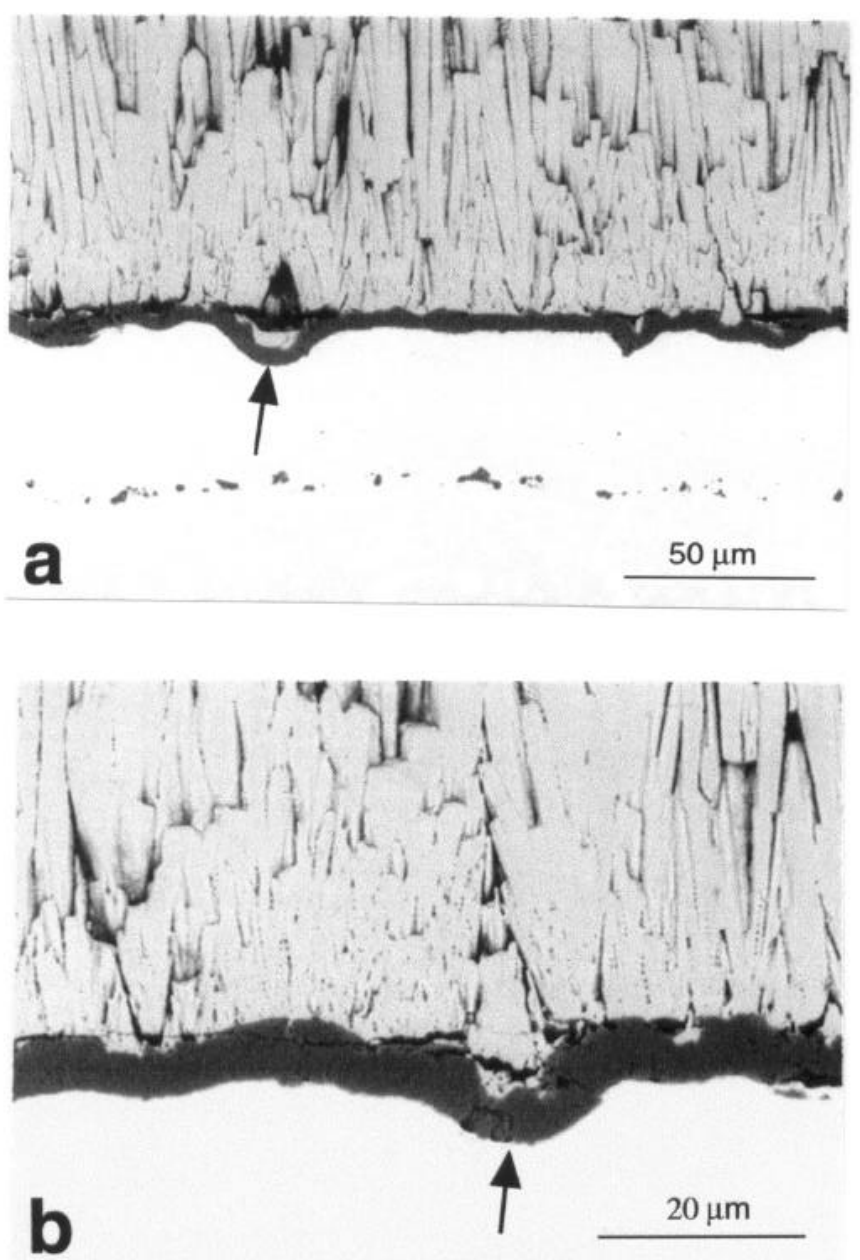

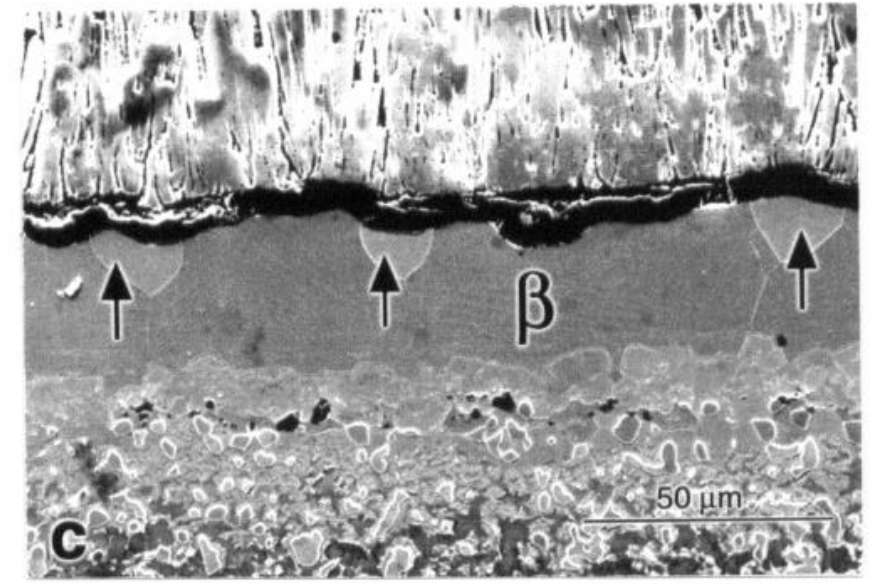

Figure 12. Scanning micrographs are presented for aluminide $\mathrm{C}$ after 758 cycles at $1100^{\circ} \mathrm{C}$. The TBC had not failed. Undulations are evident in the TGO, arrows, (a) and (b), where it is evident that some of the fragments of TBC have been broken off from the coating. The aluminide bond coat contains $\gamma^{\prime}$ phase, arrow (c), and $\beta$ phase.
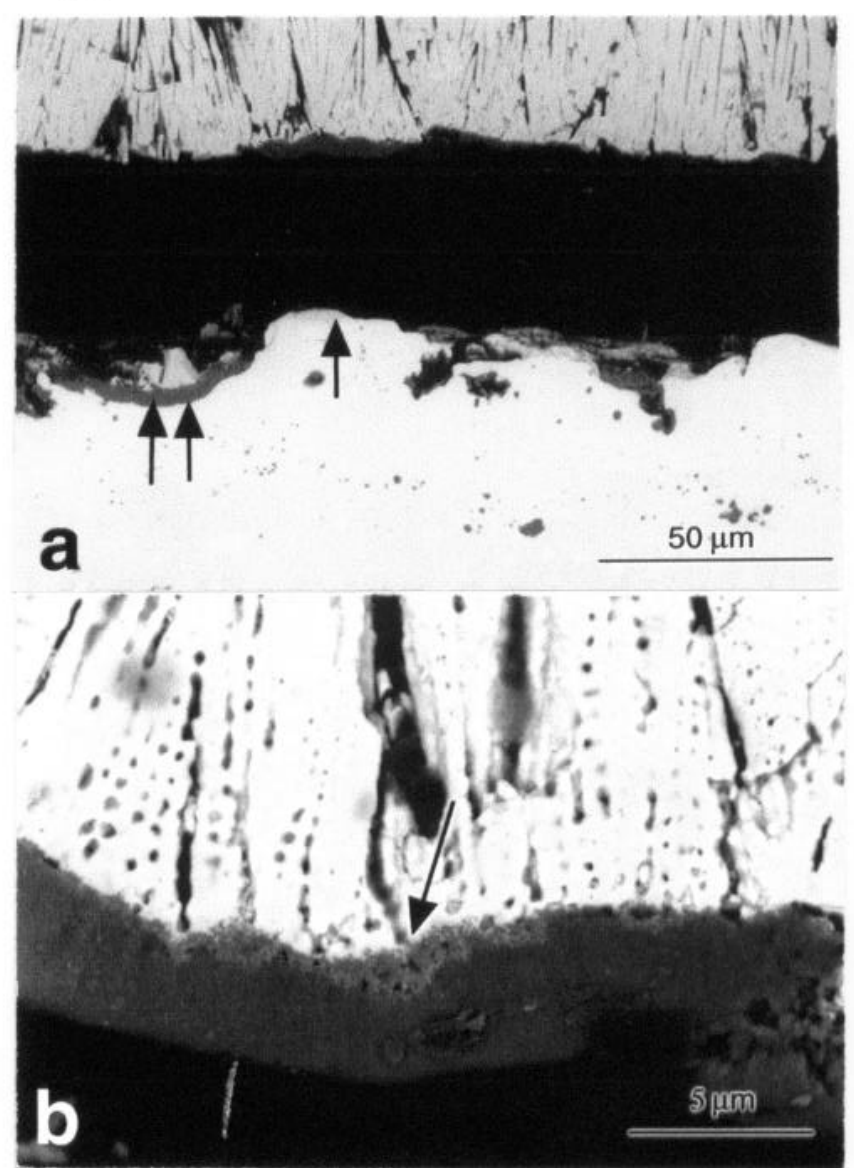

Figure 13. Scanning micrograph of platinum aluminide bond coat A after 758 cycles at $1100^{\circ} \mathrm{C}$. The TBC did not fail during testing, but became detached upon metallographic preparation. It is evident that failure has involved fracture at the TGO-bond coat interface arrow (a), as well as fracture in the TGO and TBC,double arrows, (a). At times an outer zone was apparent in the TGO extending into the TBC, arrow, (b). 


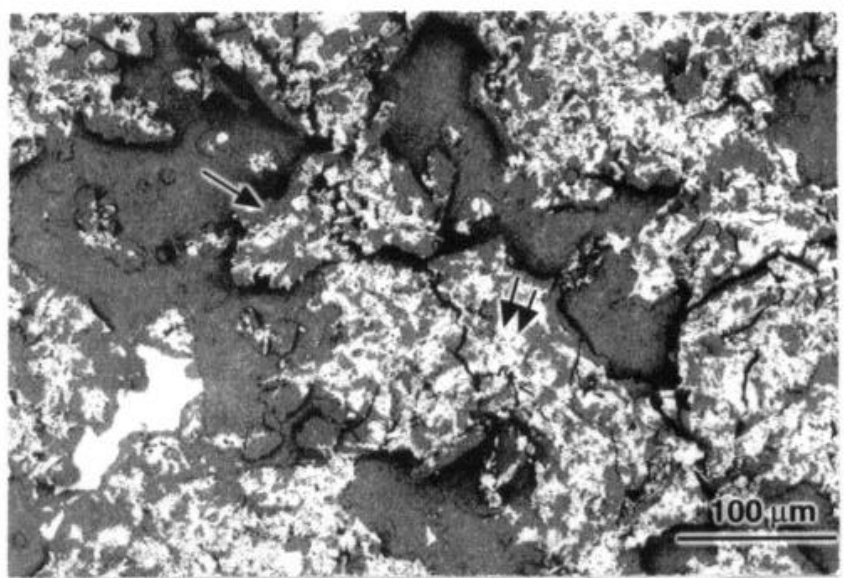

Figure 14. Scanning micrograph of typical platinum aluminide bond coat surface exposed after spalling of the TBC. The fracture occurred in the TGO(arrow) and the TBC (double arrows) as well as along the TGO-bond coat interface. The failure occurred during cyclic oxidation and the bare bond coat has been oxidized.

The failure of the TBCs on the platinum aluminide bond coats are believed to initiate in the TBC at ratchets in the TGO, Figure $12 \mathrm{~b}$. The cracks then propagate in the TBC and TGO as well as in the TGO-bond coat interface. Wrinkling of the bond coat may be a factor in initiating such failures, and more strong aluminide bond coats could extend coating lives. While aluminum depletion has been observed in these bond coats, it is not obvious that aluminum depletion, nor the presence of substrate elements, is playing a role in the failures of the TBCs on the platinum aluminide bond coats. Gell et al (8) have found that TBCs on platinum aluminide bond coats failed by crack initiation at boundaries in the aluminide bond coat at which preferential oxidation had occurred. In this investigation the bond coats were not grit blasted prior to TBC deposition, in contrast to the present study. It has been found that grit blasting inhibits the preferential oxidation of grain boundaries in aluminide bond coats (5).

\section{Conclusions}

The lives of TBCs on MCrAlY bond coats exposed to oxidizing conditions were substantially shorter than those on platinum aluminide bond coats. It is proposed that this may have been caused by the presence of other oxides than alumina on the as processed MCrAIY bond coats. It is not clear that failures of Generation III TBCs occur due to decreased interfacial toughness of the TGO-bond coat interface. Other factors such as ratcheting of the bond coat and the TGO may play significant roles in some failures. Processing conditions play a crucial role in TBC performances. Consequently, there probably are a number of different mechanisms by which Generation III TBCs fail. TBC performances should be increased by utilizing proper processing procedures.

\section{Acknowledgements}

This work was suppoted by AFOSR(contract number F49620981-0221). The authors are grateful to GE Aircraft Engines(Ro Grylls and D. Wortman) and to Praxair Surface Technologies (A.
Bolcavage and $\mathrm{T}$. Taylor) for specimen preparation and numerous technical discussions.

\section{$\underline{\text { References }}$}

1. S. Bose and J. DeMasi-Marcin, "Thermal Barrier Coating Experience in Gas Turbine Engines at Pratt \& Whitney" Thermal Barrier Coating Workshop,, Nasa Lewis Research Center, 21000 Brookpared Rd, Cleveland, OH, 44135. NASA Conference Publication 3312, 63 - 77, (1995).

2. A. Maricochi et al, "PVD TBC Experience on GE Aircraft Engines" ibid, $79-89$.

3. Z. Mutasim, C. Remlinger and W. Brentnall, "Characterization of Plasma Sprayed and Electron Beam Physical Vapor Deposited Thermal Barrier Coatings," The American Society of Mechanical Engineers, 97 - GT - 531, June (1997).

4. J. Schaeffer, " The Effect of Alumina Phase Transformations on Thermal Barrier Coating Durability", TBC 1997 Workshop, Nasa Lewis Research Center, 21000 Brookpared Rd, Cleveland, $\mathrm{OH}, 44135$. 99-108, (1997)

5. M. J. Stiger, et al "Thermal Barrier Coatings for the $21^{\text {st }}$ Century," Zeitschrift für Metallkunde, 90 (1999), 12, pp. 1069 1078 .

6. A. Vasinonta and J. L. Beuth, "Measurement of Interfacial Toughness in Thermal Barrier Coating Systems by Indentation," Submitted to: Journal of the Mechanics and Physics of Solids, April 1999.

7. M. Gell et al, "Mechanism of Spalling in Platinum Aluminide/Electron Beam Physical Vapor Deposition Thermal Barrier Coatings," Met. and Mat. Trans. A, 30A, (1999), pp. 427 435 . 